$09,11,13$

\title{
О фотоиндуцированной гетероструктуре в пленке двуокиси ванадия
}

\author{
(C) А.Л. Семенов \\ Ульяновский государственный университет, \\ Ульяновск, Россия \\ E-mail: smnv@mail.ru \\ Поступила в Редакцию 18 июня 2019 г. \\ В окончательной редакции 18 июня 2019 г. \\ Принята к публикации 1 августа 2019 г.
}

\begin{abstract}
Теоретически исследован нетепловой фотоиндуцированный фазовый переход полупроводник-металл, протекающий за время $\Delta t<1 \mathrm{ps}$ в пленке двуокиси ванадия на алюминиевой подложке. Показано, что под действием короткого лазерного импульса в пленке $\mathrm{VO}_{2}$ образуется структура из металлических и полупроводниковых слоев, параллельных подложке. Получена зависимость толщины слоев от плотности энергии $W$ лазерного импульса. Построена диаграмма, определяющая число слоев в зависимости от плотности энергии $W$ лазерного импульса и толщины $a$ пленки. Проведено сравнение с экспериментальными данными.
\end{abstract}

Ключевые слова: Фотоиндуцированный фазовый переход, фазовый переход полупроводник-металл, пленка двуокиси ванадия, гетероструктура полупроводник-металл.

DOI: 10.21883/FTT.2020.01.48751.519

\section{1. Введение}

В работе [1] построена теория гетероструктуры, образующейся в пленке $\mathrm{VO}_{2}$ на алюминиевой подложке под действием короткого лазерного импульса. В основе теории лежит учет интерференции падающего и отраженного от подложки возбуждающего светового импульса. Это ведет к неоднородному возбуждению электронной подсистемы полупроводниковой пленки и, как следствие, формированию в ней металлических слоев. В предельном случае толстых пленок теория согласуется с экспериментом [2].

В настоящей работе в рамках теории [1] теоретически исследовано влияние толщины $a$ пленки $\mathrm{VO}_{2}$ на алюминиевой подложке и плотности энергии $W$ короткого лазерного импульса на толщину образующихся металлических и полупроводниковых слоев. В переменных $a$ и $W$ построена диаграмма, показывающая, из какого количества слоев состоит гетероструктура.

\section{2. Основные уравнения}

Введем систему координат так, что ось $z$ направлена в глубь среды перпендикулярно поверхности пленки. На границе пленка-воздух $z=0$, на границе пленка-подложка $z=a$. Короткий лазерный импульс, распространяющийся вдоль оси $z$, возбуждает в пленке двуокиси ванадия на подложке неравновесные дырки с концентрацией [1]

$$
\begin{aligned}
p_{0}= & \frac{4\left|n_{2}\right| W}{\hbar \omega\left|1+n_{2}+\chi\left(1-n_{2}\right)^{2}\right|}\left(\alpha \cos (\varphi)\left(e^{-\alpha z}+|\chi|^{2} e^{\alpha z}\right)\right. \\
& \left.+4 \beta|\chi| \sin (\varphi) \cos \left(2 \beta z-\varphi_{1}\right)\right)
\end{aligned}
$$

где $W$ - плотность энергии лазерного импульса, $n_{2}$ - комплексный показатель преломления пленки, $\hbar \omega-$ энергия фотонов,

$$
\chi=\frac{k_{2}-k_{3}}{k_{2}+k_{3}} \exp \left(2 i k_{2} \alpha\right)
$$

$k_{2}, k_{3}$ - волновое число в пленке и подложке соответственно, $a-$ толщина пленки, $\alpha=2 \operatorname{Im}\left(k_{2}\right)-$ коэффициент оптического поглощения пленки, $\beta=\operatorname{Re}\left(k_{2}\right)$, $\varphi=\arg \left(k_{2}\right), \varphi_{1}=\arg (\chi)$. При записи выражения (1) предполагается, что показатель преломления воздуха $n_{1} \approx 1$. Первое слагаемое в правой части уравнения (1) обусловлено волной, бегущей вдоль оси $z$, второе против оси $z$, третье - интерференцией этих волн.

Нетепловой фотоиндуцированный фазовый переход полупроводник-металл в двуокиси ванадия происходит при условии [1]:

$$
p_{0} \geq p_{c}
$$

где

$$
p_{c}=\frac{\xi_{0} N}{2 \pi}
$$

- критическая концентрация фотовозбужденных дырок, $\xi_{0}$ - параметр порядка фазового перехода металлполупроводник в низкотемпературной полупроводниковой фазе, $N$ - концентрация атомов ванадия в $\mathrm{VO}_{2}$.

Используя соотношения (1), (3), находим критическую плотность энергии лазерного импульса:

$$
\begin{array}{r}
W_{c}=\frac{p_{c} \hbar \omega\left|1+n_{2}+\chi\left(1-n_{2}\right)\right|^{2}}{4\left|n_{2}\right|\left(\alpha \cos (\varphi)\left(e^{-\alpha a}+|\chi|^{2} e^{\alpha z}\right)+\right.} \\
\left.\quad+4 \beta|\chi| \sin (\varphi) \cos \left(2 \beta z-\varphi_{1}\right)\right)
\end{array}
$$


Нетепловой фотоиндуцированный фазовый переход полупроводник-металл в точке $z$ пленки двуокиси ванадия происходит при условии

$$
W \geq W_{c} .
$$

Соотношение

$$
W=W_{c}(z)
$$

с учетом уравнения (5) определяет зависимость координаты $z$ границы между металлической и полупроводниковой фазами от плотности энергии $W$ лазерного импульса.

\section{3. Численные расчеты, обсуждение полученных результатов и сравнение с экспериментом}

При выполнении численных расчетов используем следующие значения параметров двуокиси ванадия [3-5]: концентрация атомов ванадия $N \approx 3 \cdot 10^{22} \mathrm{~cm}^{-3}$, параметр порядка фазового перехода металл-полупроводник в низкотемпературной полупроводниковой фазе $\xi_{0} \approx 0.5$, энергия фотонов $\hbar \omega \approx 1.55 \mathrm{eV}$ (длина волны в вакууме $\lambda \approx 800 \mathrm{~nm}$ ), комплексный показатель преломления пленки $n_{2} \approx 2.9+0.5 i[2,6]$. Рассмотрим пленку $\mathrm{VO}_{2}$ на алюминиевой подложке. Такие пленки использовались в эксперименте [7] по нетепловому фотоиндуцированному фазовому переходу полупроводник-металл. Комплексный показатель преломления алюминиевой подложки $n_{3} \approx 2.7+8.3 i[8]$.

Из формулы (4) получаем критическую концентрацию фотовозбужденных дырок $p_{c} \approx 2.4 \cdot 10^{21} \mathrm{~cm}^{-3}$. На рис. 1 показан график вычисленной по формулам (5), (7) зависимости координаты $z$ границы между металлической и полупроводниковой фазами от плотности энергии $W$ лазерного импульса для различных значений толщины $a$ пленки.

На рис. 1 видно, что при $W>2.6 \mathrm{~mJ} / \mathrm{cm}^{2}$ на поверхности пленки толщины $a=50 \mathrm{~nm}$ образуется металлический слой с толщиной $z$. Граничащий с подложкой полупроводниковый слой имеет толщину $a-z$. В пленке с толщиной $a=120 \mathrm{~nm}$ металлический слой образуется в середине пленки при $W>10 \mathrm{~mJ} / \mathrm{cm}^{2}$. Металлический слой имеет толщину $z_{2}-z_{1}$; где $z_{1}, z_{2}-$ нижняя и верхняя ветви зависимости $z(W)$. Толщины полупроводниковых слоев, граничащих с воздухом и подложкой, равны соответственно $z_{1}$ и $a-z_{2}$. При $W \approx 26 \mathrm{~mJ} / \mathrm{cm}^{2}$ полупроводниковый слой, граничащий с воздухом, исчезает. Для всех толщин а пленки при увеличении $W$ толщина металлических слоев возрастает, а полупроводниковых уменьшается. Слой, граничащий с подложкой, всегда полупроводниковый.

С увеличением толщины пленки влияние подложки снижается, поскольку из-за затухания уменьшается амплитуда отраженной от подложки волны. Для пленок с толщиной $a>500 \mathrm{~nm}$ зависимость $z(W)$ почти не

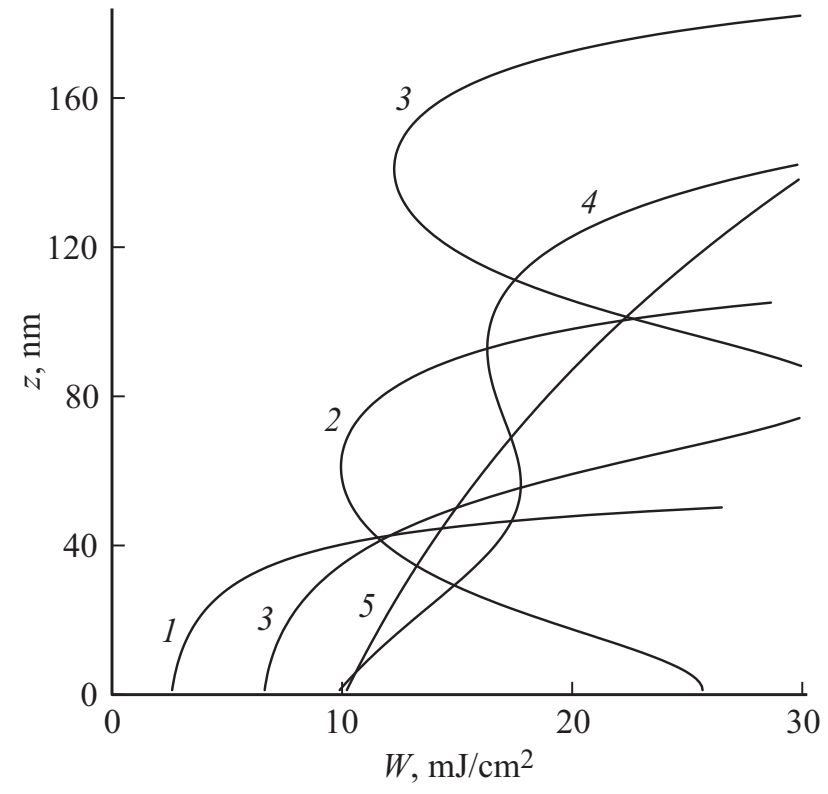

Рис. 1. Зависимость координаты $z$ границы между металлической и полупроводниковой фазами в пленке $\mathrm{VO}_{2}$ от плотности энергии $W$ лазерного импульса для значений толщины пленки $a=50,120,200,300,1000 \mathrm{~nm}$ (кривые $1-5$ соответственно.)

отличается от кривой 5 на рис. 1. В этом случае металлический слой на поверхности пленки формируется при $W>W_{c} \approx 10 \mathrm{~mJ} / \mathrm{cm}^{2}$, а при $W \approx 15 \mathrm{~mJ} / \mathrm{cm}^{2}$ образуется металлический слой толщины $d \approx 50 \mathrm{~nm}$. Эти расчетные значения согласуются с экспериментальными данными $W_{c} \approx 12 \mathrm{~mJ} / \mathrm{cm}^{2}$ и $d \approx 50 \mathrm{~nm}$, измеренными для монокристаллов $\mathrm{VO}_{2}[2]$.

На рис. 1 видно, что при увеличении $W$ образование новых металлических слоев или исчезновение полупроводниковых слоев происходит либо на поверхности пленки двуокиси ванадия, где

$$
z=0
$$

либо в точках $z$, где

$$
d W / d z=0 .
$$

Из уравнений (5), (7), (8) получаем

$$
W=\frac{p_{c} \hbar \omega\left|1+n_{2}+\chi\left(1-n_{2}\right)\right|^{2}}{4\left|n_{2}\right|\left(\alpha \cos (\varphi)\left(1+|\chi|^{2}\right)+4 \beta|\chi| \sin (\varphi) \cos \left(\varphi_{1}\right)\right)} .
$$

Из уравнений (5), (7), (9) находим

$$
\begin{aligned}
& \alpha^{2} \cos (\varphi)\left(|\chi|^{2} e^{\alpha z}-e^{-\alpha z}\right) \\
& \quad-8 \beta^{2}|\chi| \sin (\varphi) \sin \left(2 \beta z-\varphi_{1}\right)=0 .
\end{aligned}
$$

Кривые, описываемые уравнением (10) и системой уравнений (5), (7), (11), показаны на рис. 2. Эти кривые в переменных $(a, W)$ разделяют области, соответствующие гетероструктурам с различным количеством слоев. 


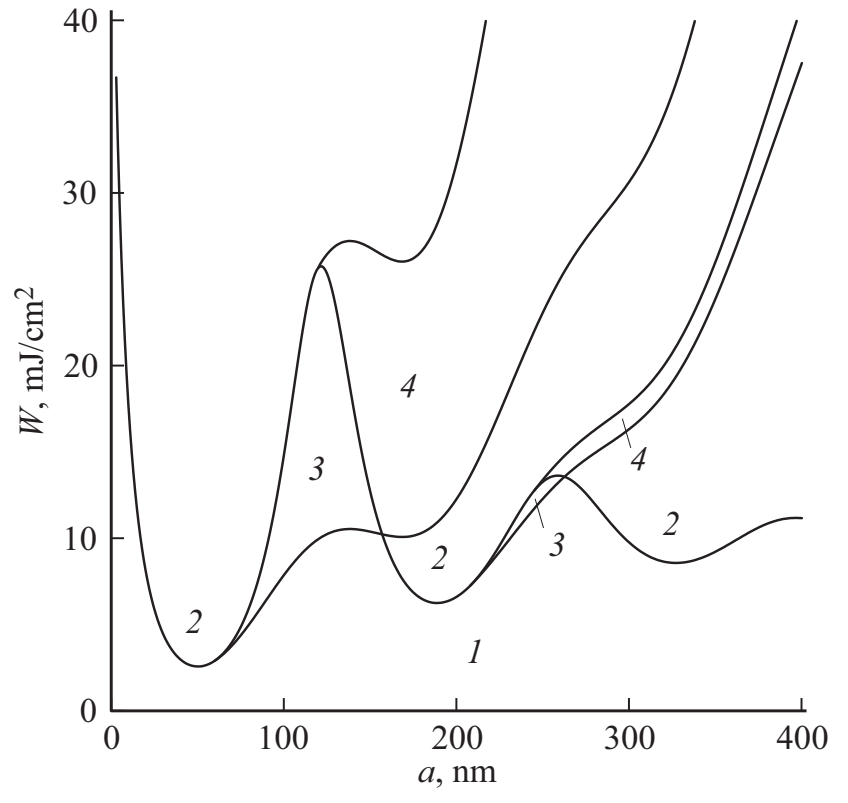

Pис. 2. Диаграмма фотоиндуцированной гетероструктуры в переменных толщина пленки $a-$ плотность энергии лазерного импульса $W$. Цифры на диаграмме показывают число слоев в гетероструктуре при данных $a$ и $W$.

Цифры на диаграмме обозначают число слоев в структуре при данных $a$ и $W$. На рис. 2 видно, что в зависимости от $a$ и $W$ образуется одна из четырех структур: 1) полупроводник, 2) металл-полупроводник, 3) полупроводник-металл-полупроводник, 4) металл-полупроводник-металл-полупроводник.

\section{4. Заключение}

В настоящей работе показано, что под действием короткого лазерного импульса в пленке двуокиси ванадия на алюминиевой подложке образуется структура, содержащая металлические и полупроводниковые слои. Число слоев и их толщина зависят от плотности энергии лазерного импульса и толщины пленки (см. рис. 1, 2). Наименьшая критическая плотность $2.6 \mathrm{~mJ} / \mathrm{cm}^{2}$, при превышении которой происходит нетепловой фотоиндуцированный фазовый переход полупроводник-металл, достигается на поверхности пленки толщины $50 \mathrm{~nm}$ (см. рис. 2).

\section{Конфликт интересов}

Автор заявляет, что у него нет конфликта интересов.

\section{Список литературы}

[1] А.Л. Семенов. ФТТ 59, 2, 341 (2017).

[2] A. Cavalleri, Cs. Toth, C.W. Siders, J.A. Squier, F. Raksi, P. Forget, J.C. Kieffer. Phys. Rev. Lett. 87, 23, 237401 (2001).
[3] А.А. Бугаев, Б.П. Захарченя, Ф.А. Чудновский. Фазовый переход металл-полупроводник и его применение. Наука, Л. (1979).

[4] А.Л. Семенов. ЖЭТФ 117, 6, 1175 (2000).

[5] А.Л. Семенов. ФТТ 42, 10, 1842 (2000).

[6] A. Cavalleri, Th. Dekorsy, H.H. Chong, J.C. Kieffer, R.W. Schoenlein. http://www.arxiv.org/cond-mat/0403214; Phys. Rev. B 70, 12, 161102(R) (2004).

[7] А.А. Бугаев, В.В. Гудялис, Б.П. Захарченя, Ф.А. Чудновский. Письма в ЖЭТФ 34, 8, 452 (1981).

[8] В.М. Золотарев, В.Н. Морозов, Е.В. Смирнова. Оптические постоянные природных и технических сред. Химия, Л. (1984). C. 182.

Редактор Т.Н. Василевская 